\title{
Applying MOOCocracy learning culture themes to improve digital course design and online learner engagement
}

\author{
Babatunde Akinkuolie ${ }^{1} \cdot$ Mitchell Shortt $^{1}$ (D)
}

Accepted: 29 December 2020 / Published online: 14 January 2021

(c) Association for Educational Communications and Technology 2021

\begin{abstract}
This piece is a short response to Loizzo and Ertmer's (2016) MOOCocracy: the learning culture of massive open online courses for the special issue: Shifting to Digital: Informing the rapid development, deployment, and future of teaching and learning. Key ideas, value, and future research implications are addressed in relation to MOOC design using the MOOCocracy themes.
\end{abstract}

Keywords Massively open online courses $\cdot$ MOOC $\cdot$ MOOCocracy $\cdot$ Online learning culture $\cdot$ Online course design

Massively open online courses (MOOCs) are an increasingly popular way to connect potentially thousands of learners online. Loizzo and Ertmer (2016) conducted their rigorous virtual ethnography several years ago, but their research is currently pertinent given the COVID-19 pandemic-Practically all educational institutions are exploring shifting to digital settings. Through taking two Coursera MOOCs and interviewing 12 adult learners, the authors develop six online learning culture themes that they label MOOCocracy. The themes are: MOOC students are critical consumers of education, MOOCs enable social media mentalities, students who lurk online are also learning, instructor engagement is appreciated but not expected from students, peer review is important to reduce the instructors' workloads while simultaneously constructing knowledge, and that students are hopeful regarding the future of MOOCs. Each theme, although mainly culture-focused, contains salient contributions for digital MOOC design.

The first theme, students as critical consumers, invokes business-centered design. If we assume that students are consuming a product, then student satisfaction could increase if the class/product is congruent with student expectations (Hall 2013; Lindstrom 2008). Isabella, one of the virtual ethnography informants, confirms studentsas-critical-consumers by comparing several international MOOCs (Loizzo and

Mitchell Shortt

shortt.10@osu.edu

Babatunde Akinkuolie

akinkuolie.2@buckeyemail.osu.edu

https://dl.ehe.osu.edu/

1 Research Laboratory for Digital Learning, The Ohio State University, Columbus, USA 
Ertmer 2016, p. 1019). For design, then, the challenge is adapting a MOOC to adhere to as many student expectations as possible to satisfy students. This might be achieved, according to Loizzo and Ertmer's (2016) results, by designing MOOCs to fit typical student expectations. For example, Anne, another informant, laments that the Human Trafficking MOOC was shorter/atypical compared to other MOOCs she has taken and seemed dissatisfied. Therefore, the Human Trafficking MOOC would likely benefit from matching the length of other MOOCs. If MOOC students (i.e. critical consumers) have general ideas of what a MOOC should be, then that MOOC should design content based on these general ideas to increase satisfaction (Anderson 1973).

The social media mentality of MOOCs is another business-related result because there is an aspect of habit-formation associated with social media (Duhigg 2012; Su et al. 2019). Although Loizzo and Ertmer (2016) reported that all the informants posted less than 10 times, the social-media mentality theme might still be utilized to make MOOCs more engaging. MOOC designers might take a design idea from Snapchat and Instagram apps by incorporating a special swipe down/scrolling function for online forums accessed via smartphone. This function is meant to mimic a slot machine (Laeder 2018; Schüll 2014). Online engagement might increase in this regard, but it important to not overdo social-media designs so that students' lives are not disrupted from inadvertent MOOC addiction (King et al. 2014).

Loizzo and Ertmer (2016) describe a type of online learning behavior, lurking, as a form of social learning. An instructor might then encourage both forum lurking and posting by explaining that both are of value. A MOOC instructor's online dashboard can be designed to track which students are neither lurking nor posting and automatically send participation reminders to those students. Alternatively, the instructor might send the reminder to better establish their presence, to which Loizzo and Ertmer's (2016) informants say they appreciate (Richardson et al. 2017).

Regarding instructor engagement in MOOCs, informants stated that they noticed the instructor only in some discussion threads and weekly videos. Informant Sean was even unsure of the instructor's name (Loizzo and Ertmer 2016, p. 1024). The findings for this theme suggest that attempting to improve teacher-student relations (TSR) in MOOCs have little effect due to the massive number of students; however, students might still benefit from better student-to-student interactions (Sun et al. 2019). Designers might explore discussion boards where students can reply using audio/video, which can establish rapport (Roblyer and Ekhaml 2000). Chen et al. (2019) developed and tested such a video interaction tool, named DanMOOC, and found that several beneficial online interaction factors increased.

Next, the peer review theme likely holds many applications for online instructional design (ID). Teachers spend a large amount of time grading assignments, and even students know that grading 30,000 assignments is impossible to do in a timely manner (Loizzo and Ertmer 2016). Peer review is a potential answer, but Wen and Tsai (2006) warn that attitudes vary strongly regarding peer review grading. The authors suggest Calibrated Peer Review ${ }^{\mathrm{tm}}$ to address fair grading, but the informants reveal other issues, such as language differences. If a MOOC has peer review assignments, then there should be an established language or have students indicate their language knowledge and program the MOOC system to distribute peer assignments appropriately. Alternatively, instructional designers might develop peer review assignments that rely more on non-linguistic categories such as visuals. There are many digital solutions to issues around peer review, so it is unsurprising that informants were overall hopeful for the future of digital learning. 
Although Loizzo and Ertmer's (2016) piece is useful, there are some limitations/constraints. The critical consumer theme presents some design limitations when considering the international reach of MOOCs. Consumers differ globally in terms of expectations, perceptions, and knowledge (Matsumoto et al. 2017). Additionally, if Loizzo and Ertmer (2016) had access to any student exit surveys, more MOOC artifacts, or the MOOC instructor for feedback/improvement, then those sources should be included to help provide specific information that would inform design decisions. Exit survey questions that focus on the critical consumer aspects of MOOCocracy, for example, might show common student expectations, which can, in turn, justify design improvements. Lastly, the authors need a larger sample size. Given the prevalence and massive class size of MOOCs, two courses and 12 participants might not be effective enough to represent the MOOC population (Hollands and Tirthali 2014).

Utilizing the design suggestions mentioned above, the main content features of MOOCs (videos and forums) can be enhanced to both engage students and improve learning. Future studies might replicate a virtual ethnography for culture; however, a case study might be more appropriate for more design-based research given that each MOOC is its own bounded system (Creswell and Poth 2018). Treating each MOOC as a case can offer more fine-grained results to better apply MOOCocracy themes.

\section{Compliance with ethical standards}

Conflict of interest There are no potential conflicts of interest.

Informed consent No human participants were involved.

Research involving human participants and/or animals No animals/human participants were involved.

\section{References}

Anderson, R. E. (1973). Consumer dissatisfaction: The effect of disconfirmed expectancy on perceived product performance. Journal of Marketing Research, 10(1), 38-44.

Chen, Y., Gao, Q., Yuan, Q., \& Tang, Y. (2019). Facilitating students' interaction in MOOCs through timeline-anchored discussion. International Journal of Human-Computer Interaction, 35(19), 1781-1799.

Creswell, J. W., \& Poth, C. N. (2018). Qualitative inquiry \& research design (4th ed.). Thousand Oaks, CA: Sage.

Duhigg, C. (2012). The power of habit: Why we do what we do in life and business. New York: Random House.

Hall, W. W. (2013). Consumerism and consumer complexity: Implications for unicersity teaching and teaching evaluation. Nurse Education Today, 33(7), 720-723. https://doi.org/10.1016/j.nedt2013.03.004.

Hollands, F. M., \& Tirthali, D. (2014). MOOCs: Expectations and reality (p. 138). Center for Benefit-Cost Studies of Education: Teachers College, Columbia University.

King, D. L., Delfabbro, P. H., Kaptsis, D., \& Zwaans, T. (2014). Adolescent simulated gambling via digital and social media: An emerging problem. Computers in Human Behavior, 31, 305-313.

Laeder, J. (2018). Social media and consumer culture: Addicted to the idealized consumer.

Lindstrom, M. (2008). Brand sense: Sensory secrets behind the stuff we buy. New York: Simon and Schuster.

Loizzo, J., \& Ertmer, P. A. (2016). MOOCocracy: The learning culture of massive open online courses. Educational Technology Research and Development, 64(6), 1013-1032.

Matsumoto, M., Chinen, K., \& Endo, H. (2017). Comparison of US and Japanese consumers' perceptions of remanufactured auto parts. Journal of Industrial Ecology, 21(4), 966-979. 
Richardson, J. C., Maeda, Y., Lv, J., \& Caskurlu, S. (2017). Social presence in relation to students' satisfaction and learning in the online environment: A meta-analysis. Computers in Human Behavior, 71, 402-417.

Roblyer, M. D., \& Ekhaml, L. (2000). How interactive are your distance courses? A rubric for assessing interaction in distance learning. Online Journal of Distance Learning Administration, 3(2), 1.

Schüll, N. D. (2014). Addiction by design: Machine gambling in Las Vegas. Princeton: Princeton University Press.

Su, W., Han, X., Jin, C., Yan, Y., \& Potenza, M. N. (2019). Are males more likely to be addicted to the internet than females? A meta-analysis involving 34 global jurisdictions. Computers in Human Behavior, 99, 86-100.

Sun, Y., Ni, L., Zhao, Y., Shen, X. L., \& Wang, N. (2019). Understanding students' engagement in MOOCs: An integration of self-determination theory and theory of relationship quality. British Journal of Educational Technology, 50(6), 3156-3174.

Wen, M. L., \& Tsai, C. (2006). University students' perceptions of and attitudes toward (online) peer assessment. Higher Education, 51(1), 27-44. https://doi.org/10.1007/s10734-004-6375-8.

Publisher's Note Springer Nature remains neutral with regard to jurisdictional claims in published maps and institutional affiliations.

Babatunde Akinkuolie earned his bachelor's degree in Information Technology from the Universityof Belize in Belize City, Belize. He subsequently received his master's degree in Computer Engineeringfrom National Chiao Tung University, Taiwan and an M.B.A from Southern New Hampshire University,New Hampshire. His research interests include Computer-Aided Instruction, Distance Learning, Studentcenteredlearning in digital environments and Technology Integration in Teaching and Learning.

Mitchell Shortt is a Doctoral student at The Ohio State University. He received his bachelor'sdegree from The College of Charleston in South Carolina. He subsequently earned an M.S. inInternational Management and Marketing from the University of Sheffield (United Kingdom) and anM.A. in Teaching English to Speakers of Other Languages from Saint Michael's College. His researchinterests include student motivation, teaching strategies, game-based learning, and computer-assistedlanguage learning. 